\title{
MODIFIED MODEL FOR SHEAR STRESS DISTRIBUTION USING TRI-1 LUNAR SOIL SIMULANT
}

\author{
S. Jayalekshmi, Pala Gireesh Kumar \\ Civil Engineering Department, National Institute of Technology, Tiruchirappalli, Tamil Nadu, India \\ e-mail: jaya@nitt.edu; jaynagu@gmail.com; gireeshnitt04@gmail.com
}

\begin{abstract}
In the present study, research is carried out on deriving modified analytical equations for finding shear stress distribution and known as Modified Shear Stress models (SSM) beneath plain wheels (small and large) on TRI-1 lunar soil simulant. In all four models, the Reece model, Bekker model, Wong-Reece model and Iagnemma model, normal stress and shear stress are determined, and the shear stress determination is based on the Janosi and Hanamoto (1961) model. There exists ample scope for modifying this model. A modified model for shear stress distribution is developed and the same is discussed in this paper.
\end{abstract}

Keywords: TRI-1, lunar soil simulant, modified model, shear stress distribution

\section{Introduction}

Investigating mobility performance of planetary rovers is a very difficult task due to presence of more obstacles, sloping conditions (steep, adverse) and environmental conditions that exist on the Moon/Mars. In such a case, knowing the performance and overcoming the problem (by means of optimizing wheel parameters, introducing sensors, etc.) result in giving a better performance. This can be done by calculating the performance parameters (drawbar pull DP, sinkage, torque, rolling resistance) for planetary rovers. This involves terrain parameters and wheel parameters which have to be determined in advance. In the present study, two plain wheels of different sizes are considered. The experiments were carried out in a fabricated single wheel test bed (Sreenivasulu, 2014) on TRI-1 lunar soil simulant.

Wheel-soil interaction has a vital role in vehicle-terrain mobility (Bekker, 1969). A rover moving (travelling) on various terrains will have different mobility characteristics. Normally, the mobility level can be determined in terms of relative performance indices (entry angle, drawbar pull coefficient, resistance coefficient, drawbar pull efficiency, tractive coefficient and tractive efficiency) and absolute performance indices (drawbar pull, driving torque and sinkage) (Liu et al., 2008; Ishigami et al., 2011). For example, the drawbar pull is very important and a positive drawbar pull indicates that the rover can generate forward motion on the terrain it is travelling (traversing), whereas a negative drawbar pull implies that forward motion is difficult or impossible, which is one of the reasons for mission failure (Wong and Reece, 1967; Iagnemma et al., 2004). Determination of absolute performance indices depends on normal stress and shear stress.

Many research works are carried out on study of grousers on motion performance (Liu et al., 2008), study of motion dynamics and control of planetary rovers (Yoshida et al., 2001), study on stability control of a wheel-lugged rover (Grand et al., 2002), terrain parameter estimation for planetary rovers (Iagnemma et al., 2004) and study on motion performance of a rover which is evaluated by its drawbar pull, driving torque which is related to normal stress and shear stress distribution produced by the wheel at the wheel-soil interface (Wong, 2001; Sutoh et al., 2010). Hence, determination of normal stresses and shear stresses plays a major role in the wheel-soil 
interaction. There are several models available, out of which four models are considered for the study (Reece, Bekker, Wong-Reece and Iagnemma model) for normal stress and shear stress distribution analysis that develops beneath the wheel when it interacts with the soil and moving on the terrain. The objective of this paper is to develop a model called the modified Shear Stress Model (SSM). A preliminary comparative study on these models resulted in refinements and culminated in the Modified Shear Stress Model (Modified SSM)

\section{Stress distribution models}

When a wheel travels over a loose soil, normal stress and shear stress develops beneath the surface. These stresses are used in the calculation of forces. The motion performance of a rover is usually evaluated by its Drawbar Pull (DP) and Driving Torque (DT), which are related to the normal and shear force distributions produced by the wheel at the wheel-soil interface. In the present study, four models are considered for analysis of wheel (small and large) that travels on TRI-1 soil simulant, and modified SSM for shear stress distribution is derived. The models considered are explained in Sections 2.1, 2.2, 2.3 and 2.4.

\subsection{Reece normal stress model}

When a wheel travels over a loose soil, normal stress and shear stress develop beneath the surface as shown in Fig. 1.

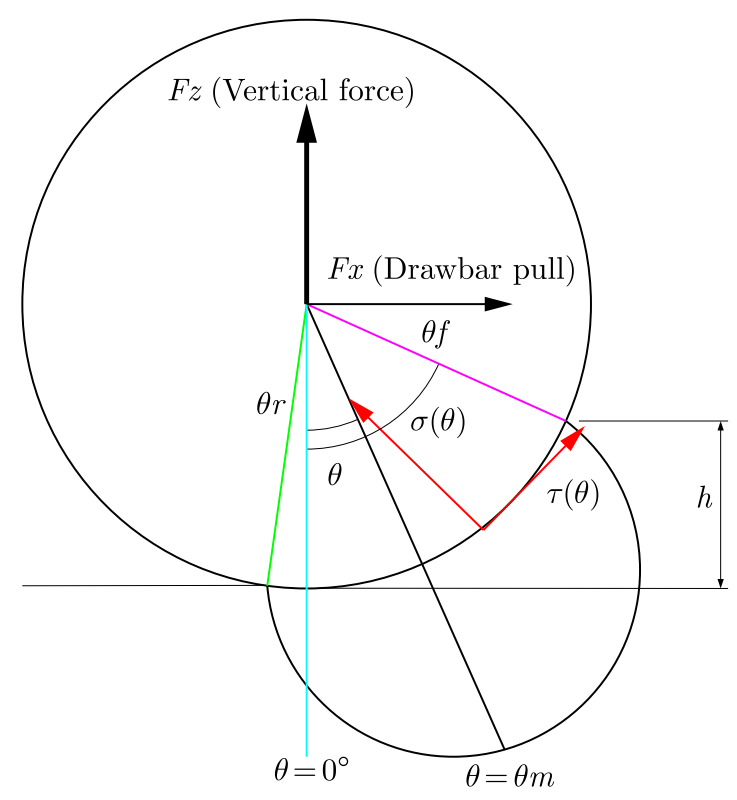

Fig. 1. Wheel-soil interaction

The maximum normal stress is found to occur at the transition point between two zones, the forward and rearward zones.

Normal stress is given as

$$
\sigma(\theta)= \begin{cases}\sigma_{\max }\left(\cos \theta-\cos \theta_{f}\right)^{n} & \text { for } \quad \theta_{m} \leqslant \theta \leqslant \theta_{f} \\ \sigma_{\max }\left[\cos \left(\theta_{f}-\frac{\theta-\theta_{r}}{\theta_{m}-\theta_{r}}\left(\theta_{f}-\theta_{m}\right)\right)-\cos \theta_{f}\right]^{n} & \text { for } \quad \theta_{r} \leqslant \theta \leqslant \theta_{m}\end{cases}
$$

where

$$
\sigma_{\max }=\left(c k_{c}+\rho k_{\phi} b\right)\left(\frac{r}{b}\right)^{n}
$$


where $h, b, r$ is the wheel sinkage, width and radius, respectively, $n$ - sinkage exponent, $c$ - cohesion stress of the soil, $\rho$ - soil bulk density, $k_{c}, k_{\phi}$ - pressure-sinkage moduli. $\theta_{f}$ is the entry angle (the angle from the vertical to the point at which the wheel initially makes contact with the soil)

$$
\theta_{f}=\cos ^{-1}\left(1-\frac{h}{r}\right)
$$

$\theta_{r}$ - departure angle (the angle from the vertical to where the wheel departs from the soil, and this value is generally assumed to be zero), i.e., $\theta_{r} \cong 0, \theta_{m}$ - maximum angle (the specific wheel angle where the normal stress is maximum)

$$
\theta_{m}=\left(a_{0}+a_{1} s\right) \theta_{f}
$$

$a_{0}$ and $a_{1}$ are parameters depending on the wheel-soil interaction $\left(a_{0} \cong 0.4,0 \leqslant a_{1} \leqslant 0.3\right.$, are assumed values as given by Wong (1965)).

Estimation of the maximum specific angle at which normal stress and shear stress are maximum can be found using Eq. (2.4) for the other models (Bekker and Wong-Reece).

The shear stress distribution model was given by Janosi and Hanamoto (1961) and the same was considered by Reece (1965) to find the shear stress developed beneath the wheel, as shown in Fig. 1.

Shear stress is given as

$$
\tau_{x}=[c+\sigma(\theta) \tan \phi]\left[1-\exp \left(-\frac{j(\theta)}{k}\right)\right]
$$

where

$$
j(\theta)=r\left[\theta_{f}-\theta-(1-s)\left(\sin \theta_{f}-\sin \theta\right)\right]
$$

and $\phi$ is the internal friction angle of the soil, $k$ - shear deformation modulus (depending on the shape of the wheel surface), $j$ - soil deformation, $s$ - wheel slip (given as the ratio of the wheel width to the wheel radius).

Similarly, the same Janosi shear stress distribution model was used to determine shear stresses for the normal stress distribution models considered by Reece, Bekker, Wong-Reece and Iagnemma.

\subsection{Bekker normal stress model}

When a wheel rolls on a loose soil, normal and shear stresses are generated under the wheel. These stresses are used in the calculation of the forces. The stresses are modeled as shown in Fig. 1.

Normal stress is given as

$$
\sigma(\theta)= \begin{cases}\sigma_{\max }\left(\frac{\cos \theta-\cos \theta_{f}}{\cos \theta_{m}-\cos \theta_{f}}\right)^{n} & \text { for } \quad \theta_{m}<\theta<\theta_{f} \\ \sigma_{\max }\left[\frac{\cos \left(\theta_{f}-\frac{\theta-\theta_{r}}{\theta_{m}-\theta_{r}}\left(\theta_{f}-\theta_{m}\right)\right)-\cos \theta_{f}}{\cos \theta_{m}-\cos \theta_{f}}\right]^{n} & \text { for } \quad \theta_{r}<\theta<\theta_{m}\end{cases}
$$

where

$$
\sigma_{\max }=\left(c k+c+\rho k_{\phi} b\right)\left(\frac{r}{b}\right)^{n}\left(\cos \theta_{m}-\cos \theta_{f}\right)^{n}
$$

and $h, b, r$ are the wheel sinkage, width and radius, respectively, $n$ - soil sinkage exponent, $c$ - cohesion stress of the soil, $\rho$ - soil bulk density, $k_{c}, k_{\phi}$ - cohesion and friction modulus 
coefficients. $\theta_{f}$ and $\theta_{r}$ are the entry and exit angles along the wheel surface, and are functions of the soil compaction and recovery. The values for $\theta_{f}$ and $\theta_{r}$ are obtained as

$$
\theta_{f}=\cos ^{-1}\left(1-\frac{h}{r}\right) \quad \theta_{r}=\cos ^{-1}\left(1-\frac{k h}{r}\right)
$$

where $h$ defines how much the wheel initially compacts the soil when it contacts with the soil surface, $k h$ defines how much the soil recovers in height following the wheel when it departs the soil surface, $k$ is the wheel sinkage ratio (which denotes the ratio between the front and rear sinkages of the wheel).

The value of $k$ depends on the wheel surface pattern, slip ratio and soil characteristics. The value of $k$ lies below 1.0 when soil compaction occurs, but can be more than 1.0 when the soil is dug by the wheel and transported to the region behind the wheel (Bekker, 1969; Yoshida and Hamano, 2001).

\subsection{Wong-Reece normal stress model}

When a wheel rolls on a loose soil, normal and shear stresses are generated under the wheel. These stresses are used in the calculation of the forces. The stresses are modeled as shown in Fig. 2.

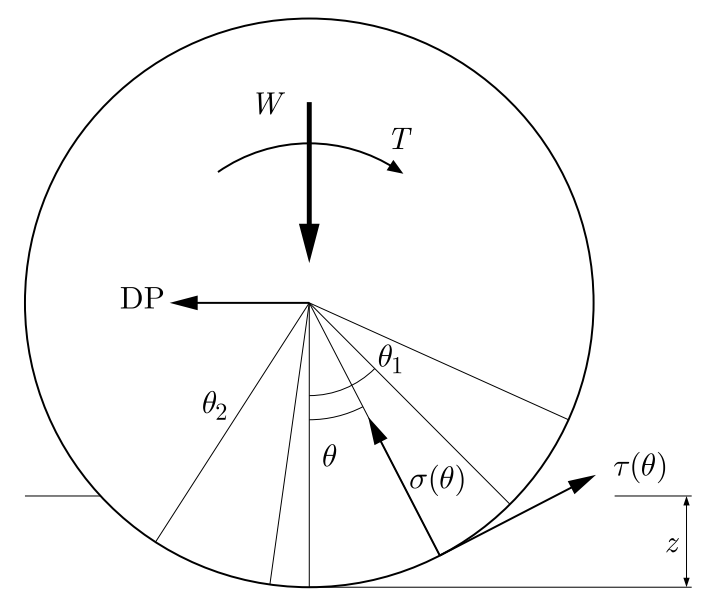

Fig. 2. Stress distribution model of plain wheel

Normal stress is given as

$$
\sigma(\theta)= \begin{cases}\left(\frac{k_{c}}{b}+k_{\phi}\right) r^{N}\left(\cos \theta-\cos \theta_{1}\right)^{N} & \text { for } \quad \theta_{m} \leqslant \theta \leqslant \theta_{1} \\ \left(\frac{k_{c}}{b}+\rho k_{\phi}\right) r^{N}\left[\cos \left(\theta_{1}-\frac{\theta-\theta_{2}}{\theta_{m}-\theta_{2}}\left(\theta_{1}-\theta_{m}\right)\right)-\cos \theta_{1}\right]^{N} & \text { for } \quad \theta_{2} \leqslant \theta \leqslant \theta_{m}\end{cases}
$$

where

$$
N=n_{0}+n_{1} s
$$

and $n_{0}$ and $n_{1}$ are parameters related to the wheel-soil interaction, $b$ denotes wheel width, $r$ - wheel radius, $c$ - cohesion stress of the soil, $z$ - sinkage, $k_{c}, k_{\phi}$ - cohesion and friction modulus coefficients. 
For wheels without lugs, the entry and exit angles can be calculated using the following equations. $\theta_{1}$ is the entry angle (the angle from the vertical to the point at which the wheel initially makes contact with the soil)

$$
\theta_{1}=\cos ^{-1}\left(1-\frac{z}{r}\right)
$$

$\theta_{2}$ is the departure angle (the angle from the vertical to where the wheel departs from the soil, and this value is generally assumed to be zero). In this model, it is not assumed as zero, hence it can be calculated as

$$
\theta_{2}=\cos ^{-1}\left(1-\frac{k z}{r}\right)
$$

\subsection{Iagnemma normal stress nodel}

When a wheel rolls on a loose soil, radial and tangential stresses are generated under the wheel. These stresses are used in the calculation of the forces. The stresses are modeled as in Fig. 2.

Radial stress is given as

$$
\sigma(\theta)= \begin{cases}\sigma_{1}(\theta) & \text { for } \quad \theta_{m}<\theta<\theta_{1} \\ \sigma_{2}(\theta) & \text { for } \quad \theta_{2}<\theta<\theta_{m}\end{cases}
$$

where

$$
\begin{aligned}
\sigma_{1}(\theta) & =\left(\frac{k_{c}}{b}+k_{\phi}\right)\left[r\left(\cos \theta-\cos \theta_{1}\right)\right]^{n} \\
\sigma_{2}(\theta) & =\left(\frac{k_{c}}{b}+k_{\phi}\right)\left[r\left(\cos \left(\theta_{1}-\frac{\theta-\theta_{2}}{\theta_{m}-\theta_{2}}\left(\theta_{1}-\theta_{m}\right)\right)-\cos \theta_{1}\right)\right]^{n}
\end{aligned}
$$

and $z, b, r$ are the wheel sinkage, width and radius, respectively, $n$ is the sinkage exponent, $c$ - cohesion stress of the soil, $\rho$ - soil bulk density, $k_{c}, k_{\phi}$ - coefficient of cohesion and friction modulus, $\sigma_{1}$ - radial stress profile between $\theta_{1}$ and $\theta_{m}, \sigma_{2}$ - radial stress profile between $\theta_{m}$ and $\theta_{2}, \theta$ - angular location of the wheel rim, $\theta_{1}$ - entry angle (the angle from the vertical to the point at which the wheel initially makes contact with the soil)

$$
\theta_{1}=\cos ^{-1}\left(1-\frac{z}{r}\right)
$$

$\theta_{2}$ is the departure angle (the angle from the vertical to where the wheel departs from the soil, and this value is generally assumed to be zero), i.e., since $\theta_{2}$ is generally small in practice for low cohesion soils, $\theta_{2} \cong 0 . \theta_{m}$ is the maximum angle (angular location of the maximum normal stress). The location of the point of the maximum radial stress is at

$$
\theta_{m}=\frac{\theta_{1}+\theta_{2}}{2}
$$

\section{Modified stress distribution models}

Using the above normal stress models and the shear stress model for plain wheels, small wheels $(160 \mathrm{~mm} \times 32 \mathrm{~mm})$ and large wheels $(210 \mathrm{~mm} \times 50 \mathrm{~mm})$, the normal stress and shear stresses are determined and the modified shear stress distribution model is developed from the obtained results of previous models. The shear stress distribution model was given by Janosi and Hanamoto (1961) and the same model was used by Reece, Bekker, Wong and Iagnemma normal stress distribution (where the shear stress was a function of the normal stress). 
Hence, there exists space in deriving modified shear stress distribution models. The developed mathematical model for the shear stress distribution is based on the Janosi and Hanamoto (1961) model which has been used for both wheels (small: $160 \mathrm{~mm} \times 32 \mathrm{~mm}$ and large: $210 \mathrm{~mm} \times 50 \mathrm{~mm}$ ) moving on TRI-1 (Tiruchirappalli-1) soil simulant. An analytical method for predicting the shear stress distribution beneath the wheel when it interacts with the soil has been found based on the results obtained from all four models which are considered in the study. The derived shear stress model for TRI-1 soil simulant predicts the shear stress very well and close to the Janosi model. The modified shear stress model (SSM) is not a function of the normal stress, whereas the earlier one is a function of the normal stress. In this modified SSM, the constants like $A, B$ and $F$ are introduced and the model expressed is in terms of $b / R$ and the maximum specific angle $\theta_{m}$. The modified SSM for all models considered are given as below.

Model 1 (Reece model)

Table 1. Equation for the modified SSM, $A=3.409 k-0.112, B=-90.90 k+2.2361$

\begin{tabular}{|c|c|c|c|c|}
\hline No. & Condition & & $F$ & Equation for shear stress \\
\hline 1 & \multirow[t]{2}{*}{$\max$ ss $k_{1}$} & S & \multirow{2}{*}{$\frac{b d}{W}\left(64.84 \frac{b}{R}-9.635\right)$} & \multirow{12}{*}{$\begin{array}{c}\tau=F \frac{w}{b d}\left(A \frac{\theta_{m}}{\theta_{\text {ref }}}+B\right) \\
\theta_{\text {ref }}=1^{\circ} \text { (assumption) }\end{array}$} \\
\hline 2 & & $\mathrm{~L}$ & & \\
\hline 3 & \multirow[t]{2}{*}{$\min$ ss $k_{1}$} & $\bar{S}$ & $b d\left(d_{0} b\right.$ & \\
\hline 4 & & $\mathrm{~L}$ & $\bar{W}(39.25 \bar{R}-5.51)$ & \\
\hline 5 & \multirow[t]{2}{*}{$\max \operatorname{ss} k_{2}$} & $\bar{S}$ & $b d(101, b$ & \\
\hline 6 & & $\mathrm{~L}$ & $\bar{W}(164.60 \bar{R}-49.58)$ & \\
\hline 7 & \multirow[t]{2}{*}{$\min \mathrm{ss} k_{2}$} & $\mathrm{~S}$ & $b d\left(10140 \frac{b}{-3038)}\right.$ & \\
\hline 8 & & $\mathrm{~L}$ & $\bar{W}(101.40 \bar{R}-30.38)$ & \\
\hline 9 & \multirow[t]{2}{*}{$\max \operatorname{ss} k_{3}$} & $\mathrm{~S}$ & 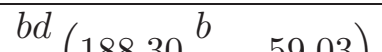 & \\
\hline 10 & & $\mathrm{~L}$ & $\bar{W}^{\left(100.00 \bar{R}^{-}\right.}$ & \\
\hline 11 & \multirow[t]{2}{*}{$\min \mathrm{ss} k_{3}$} & $\overline{\mathrm{S}}$ & $b d a b$ & \\
\hline 12 & & $\mathrm{~L}$ & $\bar{W}(113.40 \bar{R}-$ & \\
\hline
\end{tabular}

In Table 1, $A$ and $B$ are shear deformation constants (depending on $k$, shear deformation modulus obtained from a direct shear test, $k$ for TRI-1 soil simulant is $1.02 \pm 0.76 \mathrm{~cm}$ ) and are given in the above table. S denotes small wheel, L - large wheel, ss - shear stress, $W$ - wheel weight, $b$-wheel width and $d$-wheel diameter. Similarly, for other modified SSM also, it is same ( $k$ remains the same for TRI-1 soil simulant and varies for different types of simulants, $A$ and $B$ varies, $W, b$ and $d$ also vary).

For both small $(160 \mathrm{~mm} \times 32 \mathrm{~mm})$ and large wheels $(210 \mathrm{~mm} \times 50 \mathrm{~mm})$, the modified SSM is the same, where $A$ and $B$ for each model are given separately. The modified SSM is given for both minimum and maximum density. The model is the same for each case but it changes with respect to the shear deformation modulus $k$ and a factor $F$ (Table 1). Similarly, for other models, the modified SSM are as follows.

Model 2 (Bekker model)

Findings of the shear stress coefficient $F$ and shear deformation constants $A$ and $B$ are explained in Figs. 3 to 8 . The shear deformation constants are derived in terms of the shear deformation modulus for different models and are presented in these figures. 
Table 2. Equation for the modified SSM, $A=3.623 k-0.116, B=-90.90 k+2.236$

\begin{tabular}{|c|c|c|c|c|}
\hline No. & Condition & & $F$ & Equation for shear stress \\
\hline 1 & \multirow[t]{2}{*}{$\max$ ss $k_{1}$} & S & \multirow{2}{*}{$\frac{b d}{W}\left(85.94 \frac{b}{R}-18.08\right)$} & \multirow{12}{*}{$\begin{array}{c}\tau=F \frac{w}{b d}\left(A \frac{\theta_{m}}{\theta_{\text {ref }}}+B\right) \\
\theta_{\text {ref }}=1^{\circ} \text { (assumption) }\end{array}$} \\
\hline 2 & & $\mathrm{~L}$ & & \\
\hline 3 & \multirow[t]{2}{*}{$\min \operatorname{ss} k_{1}$} & $\mathrm{~S}$ & $b d_{(5295} b \quad$ 10 70$)$ & \\
\hline 4 & & $\mathrm{~L}$ & $\bar{W}(52.25 \bar{R}-10.70)$ & \\
\hline 5 & \multirow[t]{2}{*}{$\max \operatorname{ss} k_{2}$} & $\mathrm{~S}$ & $b d(17150 b \quad 5236)$ & \\
\hline 6 & & $\mathrm{~L}$ & $\bar{W}(171.50 \bar{R}-52.36)$ & \\
\hline 7 & \multirow[t]{2}{*}{$\min \mathrm{ss} k_{2}$} & $\mathrm{~S}$ & $b d\left(105.50 \frac{b}{-3201)}\right.$ & \\
\hline 8 & & $\mathrm{~L}$ & $\bar{W}(105.50 \bar{R}-32.01)$ & \\
\hline 9 & \multirow[t]{2}{*}{$\max \operatorname{ss} k_{3}$} & $\bar{S}$ & $b d d_{10100} b$ & \\
\hline 10 & & $\mathrm{~L}$ & $\bar{W}(191.00 \bar{R}-00.1$ & \\
\hline 11 & \multirow[t]{2}{*}{$\min \mathrm{ss} k_{3}$} & $\overline{\mathrm{S}}$ & $b d(-1, b$ & \\
\hline 12 & & $\mathrm{~L}$ & $\bar{W}(117.40 \bar{R}-36.79)$ & \\
\hline
\end{tabular}

Model 3 (Wong-Reece model)

Table 3. Equation for the modified SSM, $A=5.655 k-0.167, B=-116.80 k+2.770$

\begin{tabular}{|c|c|c|c|c|}
\hline No. & Condition & & $F$ & Equation for shear stress \\
\hline 1 & \multirow[t]{2}{*}{$\max \operatorname{ss} k_{1}$} & $\bar{S}$ & \multirow{2}{*}{$\frac{b d}{W}\left(8.755 \frac{b}{R}-12.36\right)$} & \multirow{12}{*}{$\begin{array}{c}\tau=F \frac{w}{b d}\left(A \frac{\theta_{m}}{\theta_{\text {ref }}}+B\right) \\
\left.\theta_{\text {ref }}=1^{\circ} \text { (assumption }\right)\end{array}$} \\
\hline 2 & & $\mathrm{~L}$ & & \\
\hline 3 & \multirow[t]{2}{*}{$\min \mathrm{ss} k_{1}$} & $\mathrm{~S}$ & $b d\left(2,{ }^{b} b\right.$ o 9$)$ & \\
\hline 4 & & $\mathrm{~L}$ & $\bar{W}\left(3.473 \frac{\bar{R}}{\mathrm{C}}-8.803\right)$ & \\
\hline 5 & \multirow[t]{2}{*}{$\max \operatorname{ss} k_{2}$} & $\mathrm{~S}$ & $b d\left(0_{0} b\right.$ & \\
\hline 6 & & $\mathrm{~L}$ & $\bar{W}(10.29 \bar{R}-12.27)$ & \\
\hline 7 & \multirow[t]{2}{*}{$\min \mathrm{ss} k_{2}$} & $\mathrm{~S}$ & $b d\left(4258 \frac{b}{-6839)}\right.$ & \\
\hline 8 & & $\bar{L}$ & $8 \bar{R}-6.839)$ & \\
\hline 9 & \multirow[t]{2}{*}{$\max \operatorname{ss} k_{3}$} & $\bar{S}$ & $b d\left(8577^{b} \quad 1818\right)$ & \\
\hline 10 & & $\mathrm{~L}$ & $\bar{W}(85.77 \bar{R}-18.48)$ & \\
\hline 11 & \multirow[t]{2}{*}{$\min \mathrm{ss} k_{3}$} & $\mathrm{~S}$ & $b d\left(5217^{b}\right.$ & \\
\hline 12 & & $\mathrm{~L}$ & $\bar{W}(52.17 \bar{R}-10.6$ & \\
\hline
\end{tabular}

The modified shear stress models have been determined and are shown in Tables 1 to 3 .

The modified shear stress model (SSM) is a function of $F, A, B$ and $F$. The shear deformation constants $A$ and $B$ shown in Figs. 3 to 8 .

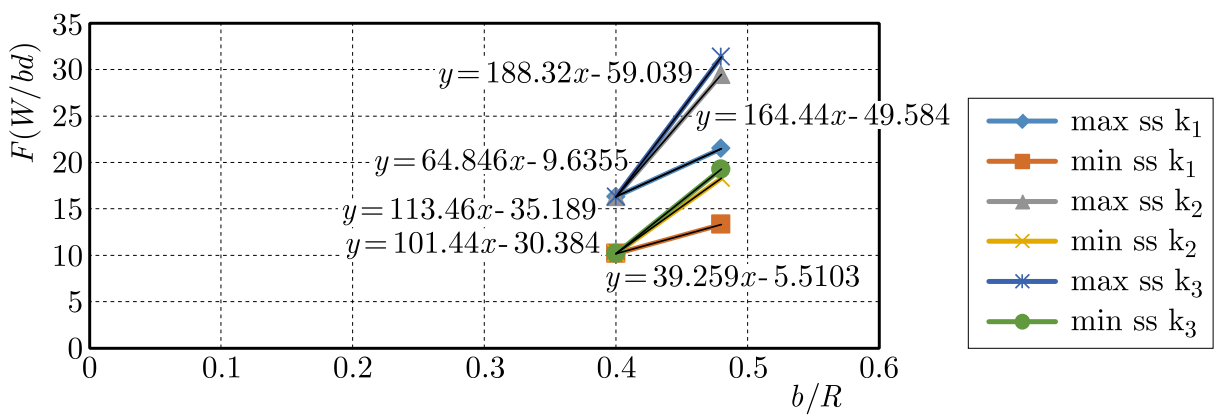

Fig. 3. Reece model - determination of $F$ 


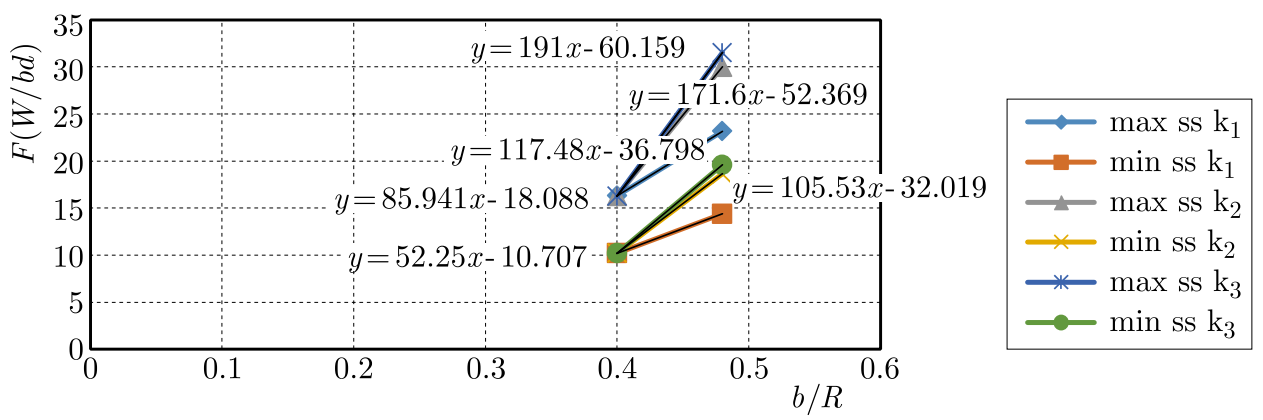

Fig. 4. Bekker model - determination of $F$

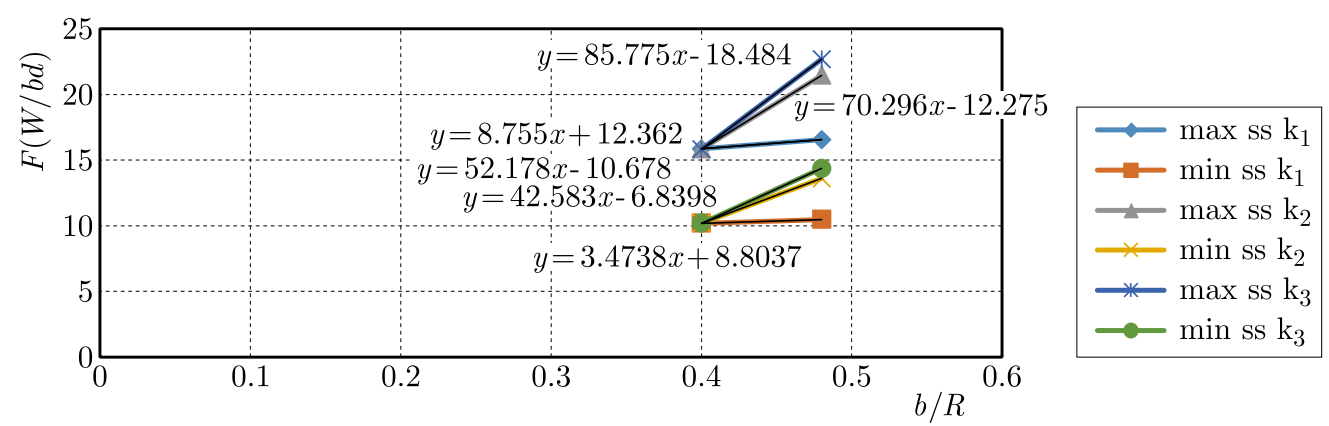

Fig. 5. Wong-Reece model - determination of $F$

(a)

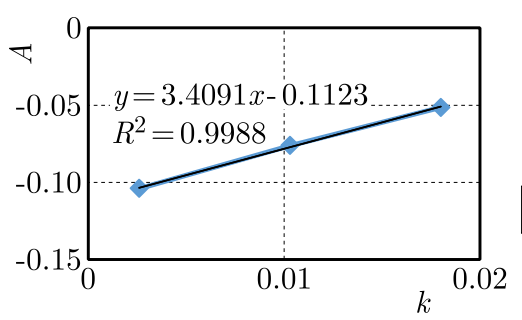

(b)

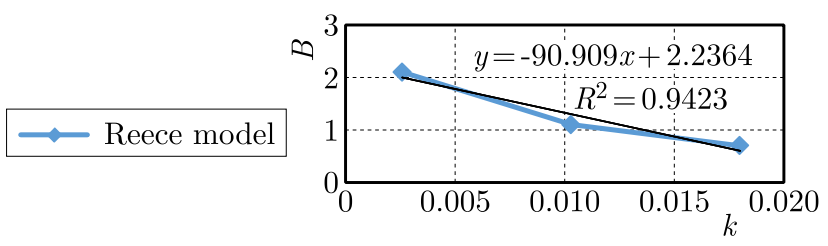

Fig. 6. Reece model - (a) determination of $A$, (b) determination of $B$

(a)

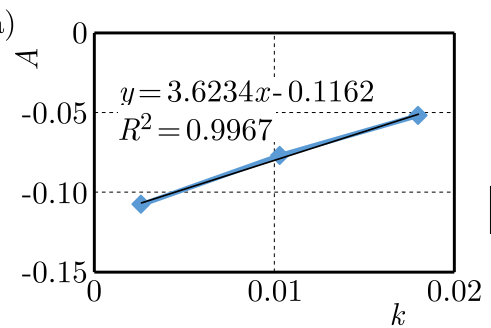

(b)

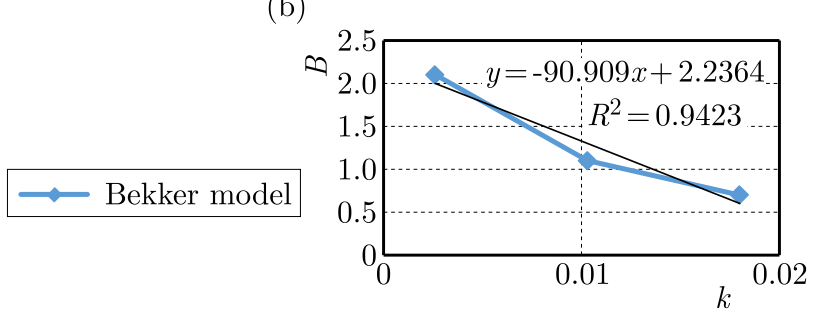

Fig. 7. Bekker model - (a) determination of $A$, (b) determination of $B$

(a)

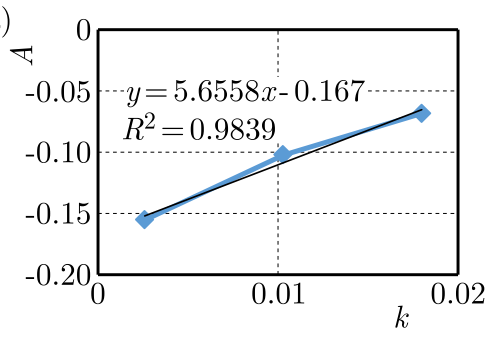

(b)

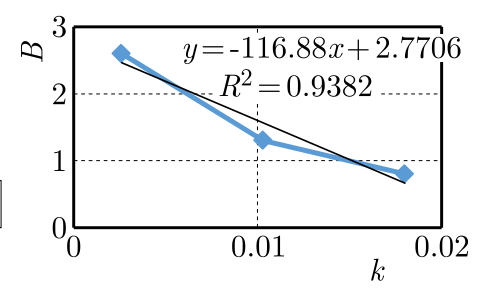

Fig. 8. Wong-Reece model - (a) determination of $A$, (b) determination of $B$ 


\section{Results and discussions}

- The shear deformation constants $A$ and $B, F$ are introduced as a function of the shear stress. The derived modified shear stress models (SSM) are presented from Tables 1 to 3, for the Reece, Bekker and Wong-Reece models, respectively.

- The modified shear stress model (SSM) is derived based on the results obtained for both small $(160 \mathrm{~mm} \times 32 \mathrm{~mm})$ and large wheels $(210 \mathrm{~mm} \times 50 \mathrm{~mm})$ from the Reece, Bekker and Wong-Reece models.

- Initially, the SSM was found for each case, later the equations were minimized by doing an extensive work and are presented in Section 3 in Tables 1 to 3.

- From Tables 1 to 3, it is found that the modified shear stress model is the same for all models (Reece, Bekker and Wong-Reece) but it varies with $F$ and shear deformation constants $A, B$. Hence, for various simulants, $F, A, B$ will be different.

- From Figs. 3 to 5 , it is found that the shear stress coefficient $F$ depends on the $b / R$ and $b d / W$ ratio, and it changes for each case in all models (Reece, Bekker and Wong-Reece) with respect to a change in the $b / R$ and $b d / W$ ratios.

- From Tables 1 to 3, it is inferred that for the maximum and minimum density, the derived equation for the modified shear stress model remains the same, but $F$ varies with respect to density irrespective of the type of wheel (both wheels - small $160 \mathrm{~mm} \times 32 \mathrm{~mm}$ and large $210 \mathrm{~mm} \times 50 \mathrm{~mm})$.

- From Figs. 6a and 6b, it is found that the shear deformation modulus $k$ is a function of the shear deformation constants $A$ and $B$. $A$ is plotted versus $k$ and $B$ versus $k$ to determine expressions for the shear deformation constants $A$ and $B$ in terms of $k$. This expression is the same and applicable to various types of simulants where $A$ and $B$ vary with respect to $k$. The obtained expression for the shear deformation constants is for the Reece model.

- Similarly, from Figs. 7 and 8, the shear deformation constants $A$ and $B$ are derived in terms of $k$ (TRI-1 soil simulant) for the remaining models (Bekker and Wong-Reece).

- From Tables 1 to 3 , it is found that the shear deformation constants $A$ and $B$ remains the same for a particular $k$ value in all models but change with respect to a change in $k$.

- The modified shear stress model (SSM) is given by the authors of this paper in the followin form

$$
\tau=F \frac{w}{b d}\left(A \frac{\theta_{m}}{\theta_{\text {ref }}}+B\right)
$$

where $A$ and $B$ are constants for both wheels (small $-160 \mathrm{~mm} \times 32 \mathrm{~mm}$ and large $210 \mathrm{~mm} \times 50 \mathrm{~mm}$ ) with respect to density (minimum $(1.15 \mathrm{~g} / \mathrm{cc}$ ) and maximum $(1.88 \mathrm{~g} / \mathrm{cc}$ ) - TRI-1 soil simulant) and varying with respect to $k$, whereas $F$ is the same for both wheels (small $-160 \mathrm{~mm} \times 32 \mathrm{~mm}$ and large $-210 \mathrm{~mm} \times 50 \mathrm{~mm}$ ) with respect to $k$ but varies with respect to density (minimum and maximum - TRI-1 soil simulant), see Tables 1 to 3 .

\section{Conclusions}

An analytical model has been developed for shear stress distribution based on the Janosi and Hanamoto (1961) shear stress distribution model. An extensive work has been carried out to derive a modified shear stress model $(\mathrm{SSM})$ for small $(160 \mathrm{~mm} \times 32 \mathrm{~mm})$ and large wheels $(210 \mathrm{~mm} \times 50 \mathrm{~mm})$ moving on TRI-1 soil simulant to find the maximum shear stress generated beneath the wheel when it interacts with the soil. Shear deformation constants $A, B$ are introduced along with a shear stress coefficient $F$, and expressions are derived for both shear 
deformation constants and $F$ for the SSM in all models. The modified shear stress model (SSM) has been derived for three models (Reece, Bekker, Wong-Reece) to determine shear stress on TRI-1 soil simulant. The results of SSM satisfy the Janosi model considered in the study. The SSM presents an alternative approach to analysis based on geometrical parameters of the wheel. The study can be extended to other simulants and wheel-soil interactions conducted on them.

\section{Acknowledgment}

The technical support received from National Institute of Technology Tiruchirappalli for the research work is gratefully acknowledged. We also acknowledge with grateful thanks to the Ministry of Human Resource Development (MHRD), India, for the Ph.D. Scholarship received to carry out the research work.

\section{References}

1. Bekker M.G., 1969, Introduction to Terrain-Vehicle Systems, Ann Arbor: University of Michigan Press

2. Ding L., Gao H., Deng Z., Nagatani K., Yoshida K., 2011, Experimental study and analysis on driving wheels' performance for planetary exploration rovers moving indeformable soil, Journal of Terramechanics, 48, 27-45

3. Grand C., Ben Amar, Plumet F., Bidaud, 2002, Stability Control of a Wheel-Lugged MiniRover, University de Paris VI

4. Iagnemma K., Kang S., Shibly H., Dubowsky S., 2004), Online terrain parameter estimation for wheeled mobile robots with application to planetary rovers, IEEE Transactions on Robotics, 20, 5, October

5. Ishigami G., Otsuki M., Kubota T., Iagnemma K., 2011, Modelling of flexible and rigid wheels for exploration rover on rough terrain, 28th International Symposium on Space Technology and Science, Okinawa, Japan, 5-12 June

6. Janosi Z., Hanamoto B., 1961, Analytical determination of drawbar pull as a function of slip for tracked vehicles in deformable soils, Proceedings of the 1st International conference on TerrainVehicle Systems, Turin, Italy, 707-736

7. Liu J., Gao H., Deng Z., 2008, Effect of straight grousers parameters on motion performance of small rigid wheel on loose sand, Information Technology Journal, 7, 8, 1125-1132

8. Sreenivasulu S., 2014, Development and Characterisation of TRI-1: an Engineered Lunar Soil Simulant and Studies on Wheel Soil Interaction, Ph.D. Thesis, Department of Civil Engineering, National Institute of Technology, Tiruchirappalli

9. Sutoh M., Yusa J., Nagatani K., Yoshida K., 2010, Travelling performance evaluation of planetary rovers on weak soil, Journal of Field Robotics, Sapporo, Japan

10. Wong J.Y., 2001, Theory of Ground Vehicles, 3rd ed., New York: Wiley-Interscience

11. Wong J.Y., Reece A,, 1967, Prediction on rigid wheel performance based on the analysis of soil-wheel stresses: Part 1. Performance of driven rigid wheels, Journal of Terramechanics, 4, 1, $81-98$

12. Yoshida K., Hamano H., 2001, Motion Dynamics and Control of a Planetary Rover With SlipBased Traction Model Robotics, Laboratory in Tsukuba Space Center, NASDA, Japan 